\title{
Research of The Excavator Form-Relieved Tooth Texture with The Medium Carbon Medium Alloy Bainite Wear-Resistant Steel
}

\author{
Xingming Zhao ${ }^{1, a}$, Shoufan Rong ${ }^{1, b}$, Xiulan Duan ${ }^{1}$, Penghui Yang ${ }^{1}$, \\ Yanhe $\mathrm{Wu}^{1}$, Xingyi $\mathrm{Li}^{1}$ \\ ${ }^{1}$ School of Materials Science and Engineering, Jiamusi University, Jiamusi, 154007, China \\ aemail: zhaoxm0212@163.com, bemail: rsfzz@163.com(corresponding author)
}

\begin{abstract}
Keywords: Bainite Steel, Heat Treatment, Cr, Isothermal Quenching, Mechanical Property
\end{abstract}
\begin{abstract}
According to the working conditions and performance requirements of relieving, this topic designed four groups of chemical composition for the text and put forward a complete set of heat treatment process. And found a set of optimal component ratio and the heat treatment process by the experimental steel of different components heat treatment and related testing and theoretical analysis. The relieving was produced by experiment steel had good comprehensive mechanical properties and this is that the excellent wear resistance, high hardness and the regularly toughness.
\end{abstract}

\section{Introduction}

Wear is a common failure mode of mechanical products, which brings huge economic losses to the society each year. Relieving [1-3] was one of the main wear of the excavators, its consumption is very large, and every year there are a number of relieving needs to import. The actual working condition of the relieving conditions is very bad, it would get abrasive action and absorb a certain amount of impact load when in contact with the material. Therefore, it has important practical significance to research on new excavator relieving material, improve the relieving under the condition of service life and reduce the economic loss caused by wear.

\section{Experimental materials and test methods}

Experimental material. The role of alloy element [4] in wear-resistant steel mainly include: strengthening ferrite, increasing and refining pearlite, perfecting the low temperature toughness of wear resistant steel, improving wear resistance of wear resistant steel, etc.

(1) Carbon: Carbon [5] is the main element in steel, it is crucial to the steel matrix and has great effect on the microstructure and mechanical properties of low alloy wear resistant cast steel. A small amount of carbon dissolved in ferrite and the rest of the carbon is existed in form of carbides.

(2) Silicon: Si can stabilize and refine austenite, it can make the nucleation and growth of bainite suppressed and also make $\mathrm{C}$ curve moves to the right.

(3) Manganese: The main role in casting wear-resistant steel of manganese is deoxidized, neutralize the harmful effect of sulfur and prevent casting defects such as hot crack.

(4) Chromium: Chromium is one of the main alloying elements in wear resistant steel, it can form alloy carbide with the carbon and iron in the steel and can dissolved in solid solution partly to strengthen the matrix, which can improve the abrasion resistance of the matrix and improve the harden-ability. Especially, it can increase the harden-ability of steel obviously go with manganese, silicon reasonably.

(5) Nickel: Nickel is solid dissolved in ferrite or works as solid solution strengthening in pearlite, it can improve the strength and hardness of the cast iron.

(6) Molybdenum: Molybdenum can improve the steel harden-ability obviously and solid solution strengthening matrix. Molybdenum prompted pearlite area and bainite separation in the $\mathrm{C}$ curve and the pearlite area goes larger, which is conducive to the formation of bainite.

To sum up, the experiment steel composition design shown in table 2.1. 
Table 2.1 The design of the experimental steel composition (wt \%)

\begin{tabular}{ccccccc}
\hline number & $\mathrm{C}$ & $\mathrm{Si}$ & $\mathrm{Mn}$ & $\mathrm{Ni}$ & $\mathrm{Mo}$ & $\mathrm{Cr}$ \\
\hline 1 & 0.5 & 1.2 & 1.2 & 0.5 & 0.3 & 2.5 \\
2 & 0.5 & 1.2 & 1.2 & 0.5 & 0.3 & 3.5 \\
3 & 0.5 & 1.2 & 1.2 & 0.5 & 0.3 & 4.5 \\
4 & 0.5 & 1.2 & 1.2 & 0.5 & 0.3 & 5.5 \\
\hline
\end{tabular}

Specimens preparation. According to the design of the components in the test steel to ingredient accurately. Smelting in medium frequency induction furnace, respectively to join the scrap steel, high carbon ferromanganese and other ferroalloys in turn, deoxidize fully with aluminum wire before pouring. Molten steel using "high temperature releasing, low temperature pouring ", released temperature control at about $1550^{\circ} \mathrm{C}$, pouring temperature control at $1480 \sim 1500^{\circ} \mathrm{C}$ [6]. This is because the right temperature to ensure that the molten iron liquid. At the same time, proper pouring temperature both can avoid the temperature is too low to produce wrinkled skin, cold insulation or casting surface is not complete and avoid castings surface serious adhering sand and oxidation due to high temperature. Cleaning and heating treatment the casting after the casting cooling. Heat treatment process [7] design is shown in Fig.1.1.

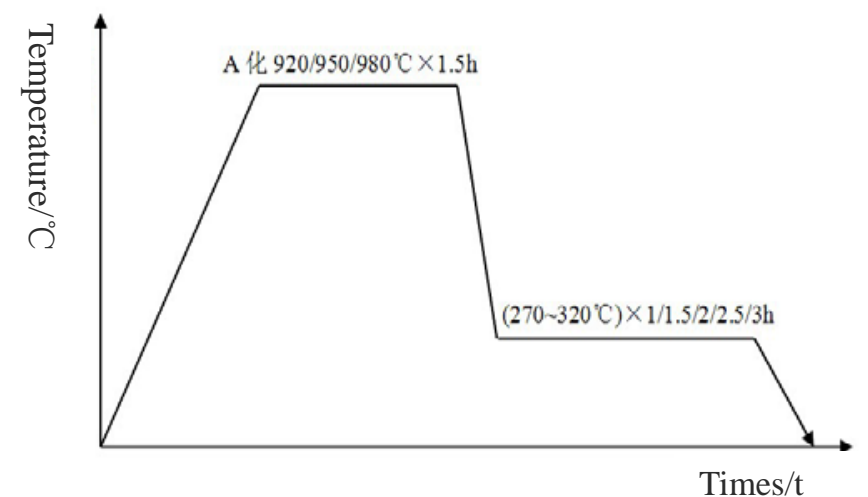

Fig.1.1 heat treatment process curve

Method of analysis and test. This experiment mainly tested the microstructure and mechanical properties of the sample after heat treatment. Impacting experiments at the ZBC-300B automatic metal pendulum impact testing machine. The hardness is tested by used HR - 150 - a rock well hardness meter.

The specimens would be metallographic grinded after impact. The test caustic is $4 \%$ nitric acid alcohol solution and specimen microstructure were observed and analyzed by Olympus optical metallographic microscope [8].

\section{Experimental results and analysis}

\section{Effect of chromium on microstructure and properties of experiment steel}

Influence of chromium on microstructure of the experiment steel. Fig.3.1 is experiment steel with different chromium contents, it can be obtained by $920^{\circ}$ Caustenitizing and $270 \sim 300^{\circ} \mathrm{C}$ isothermal quenching after 1 hour. As the figure shows that the sample of organization was the next bainite, martensite and retained austenite. With the rise of chromium content, bainite number decreased significantly. This was because the diffusion velocity of chromium in the austenite was slow and can hinder the diffusion of carbon, which can improved the stability of austenite and the harden-ability but reduced the critical cooling rate. And it can make the $\mathrm{C}$ curve moves to the right and longer incubation period [4]. 

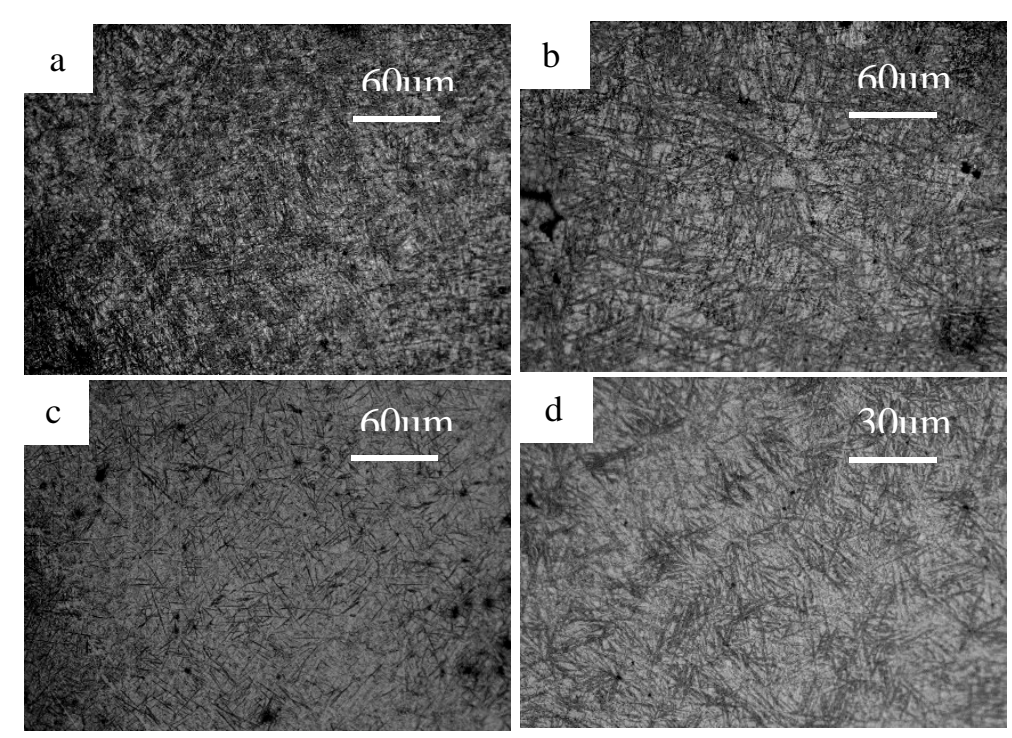

$\begin{array}{ll}\text { (a) } 2.5 w t \% & \text { (b) } 3.5 w t \%\end{array}$

(c) $4.5 \mathrm{wt} \% \quad$ (d) $5.5 \mathrm{wt} \%$

Fig.3.1 the influence of the chromium content on organization $\times 200$

Influence of chromium content on the experimental steel performance. Chromium can increase the strength, hardness and wear resistance significantly of the steel, but it can reduce toughness. Chromium is elements that forming middle strong carbide. Part of the chrome in steel replacement iron form alloy iron carbide and the other dissolve in ferrite. They have the effect of solid solution strengthening and make the carbide distribution is isolated. Chromium also improves the strength of the steel significantly. Under the condition of the same strength and hardness, chrome steel has higher plastic [9] than carbon steel.

Fig.3.2 shows experiment steel mechanical property with different chromium contents. It can be seen that with the chromium content (2.5 5.5 wt \%) improving, the experimental steel impact toughness gradually reduced but the Rockwell hardness change is not obvious. This is because that with the increase of the content of chromium, C curve moves to the right and obtain the bainite decreases ,the martensite volume and residual austenite increase at a certain time. And the both contribution to the hardness are opposite, the effect almost offset. At the same time the toughness of the matrix is reduced due to Chromium element itself and the role that using isothermal quenching heat treatment process is not very obvious when its content is more than $2.5 \%$, so its impact toughness decreasing but the hardness didn't change with the content of chromium increasing.

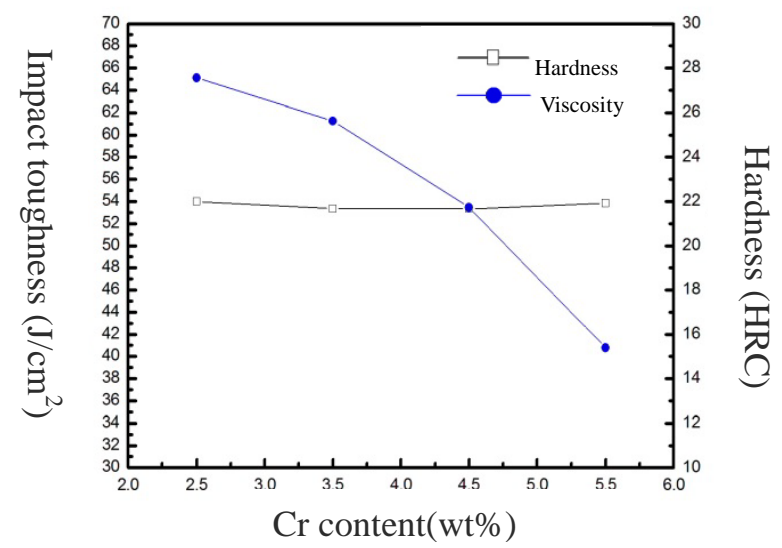

Fig.3.2 Influence of chromium content on the mechanical behavior of the experimental steel

\section{Influence of heat treatment process on experiment steel microstructure and properties}

Influence of isothermal time on experimental steel microstructure. As shown in Fig.3.3 is the chromium content in $3.5 \mathrm{wt} \%$ experimental steel samples microstructure pictures that through 920 \&ustenitizing after $270 \stackrel{\circ}{\circ}{ }^{\circ}$ a salt bath at different isothermal time. Through the graph, it can be seen that the organization formed in long and thin and flat bainite and complex organization which the residual austenite that bainite transformation into under incomplete when the isothermal time is shorter. However, with the isothermal time become longer, the bainite 
volume increase, the organization of slender B strip change coarse and wide, and the A-B composite tissue which with residual austenite film show layers alternating pattern is good for toughness [10]. Microstructures are obtained when isothermal quenching are mainly hybrid organization mixed with martensite and bainite. With the increase of isothermal time, the relative amounts of martensite are decreases and bainite is increase. The organization is homogeneous and residual austenite organization is diffuse distribution.

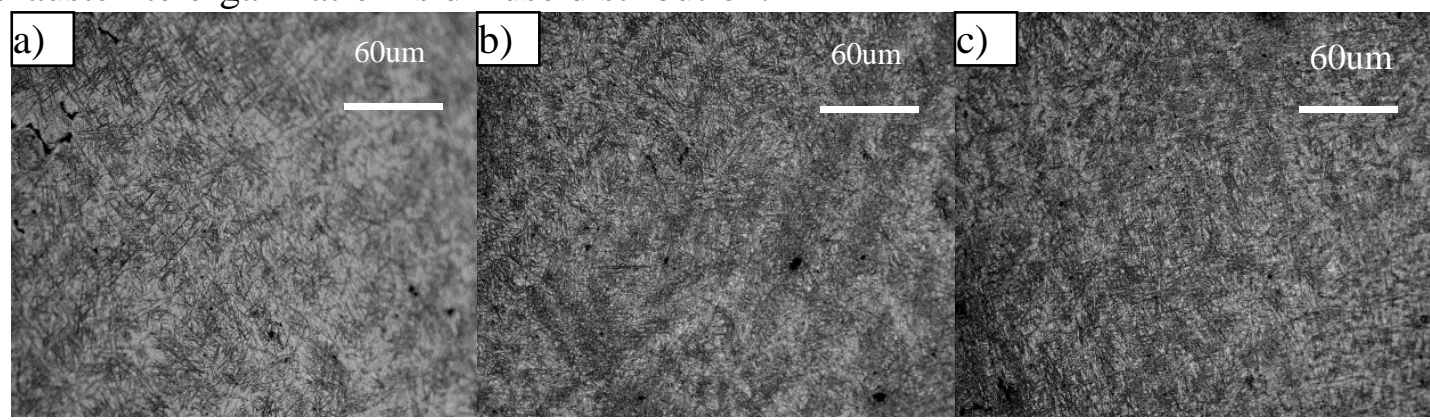
(a) $1 \mathrm{~h}$
(b) $2.5 \mathrm{~h}$
(c) $3 \mathrm{~h}$

Fig.3.3 isothermal time effect on the organization $\times 200$

Influence of isothermal time on experimental steel properties. Fig.3.4 is the experiment steel impact toughness which changed with the isothermal time. Discovered in figure, the impact toughness slightly lower after rising first with the extension of isothermal time when chromium content was $2.5 \%$ and the toughness peaked when time was $2 \mathrm{~h}$. Impact toughness in the other groups are increased with the extension of isothermal time. This is because when the chromium content is $2.5 \%$ and the isothermal time less than 2 hours, the toughness and bainite volume increase with the extension of isothermal time. The retained austenite content reduces gradually after 2 hours. So the toughness slightly decreased with the extension of isothermal time later. The other three groups of different chromium contents $(3.5 \%, 4.5 \%, 5.5 \%)$ of the experimental steel toughness continuous rise, this is due to the increase of chromium element make the $\mathrm{C}$ curve move to the right and the incubation period become longer. So the impact toughness increases with the extension of the bainite isothermal time.

Figure 3-5 is the shifty law figure which the hardness changing with the isothermal time measured in this experiment. From the figure it can be seen that the hardness without big change with the extension of isothermal time, the change range was at 48 53 HRC. This mainly because the change of hardness was rest with bainite, martensite and retained austenite content changed the result of comprehensive action. The isothermal transformation bainite volume was increasing and the residual austenite volume was losing with the extension of isothermal time, which beneficial to the improvement of the hardness. But the austenite volume that the isothermal transformation was completed to participate in martensite transformation was decreased at the same time and lead the martensite volume less in the eventual organization, which made the organization overall hardness lower. The result that the combined works led to the isothermal time had little effect on the hardness.

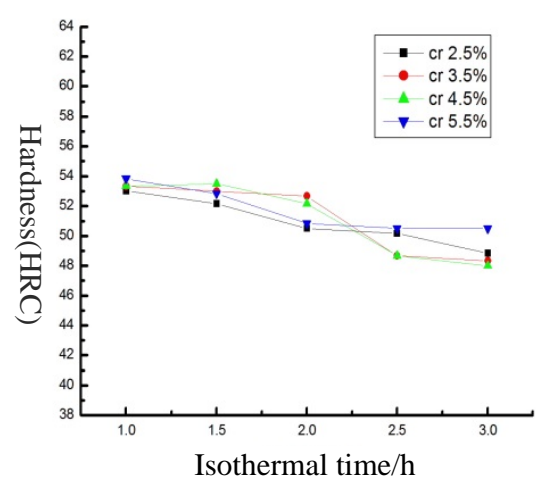

Fig.3.4 Time effects on impact toughness

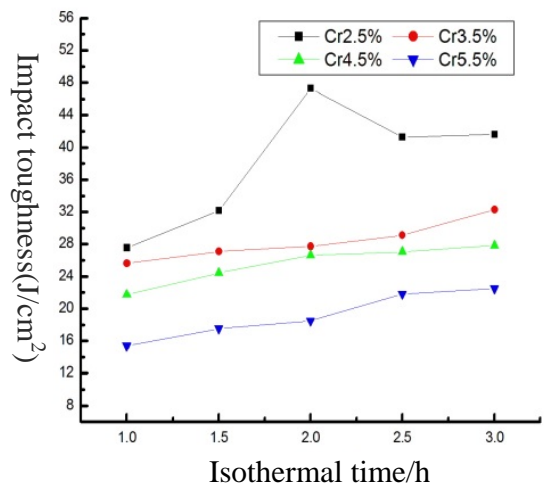

Fig.3.5 Time effect on the hardness 


\section{Conclusion}

This paper studied the effect that the chromium content and heat treatment process parameters on the mechanical properties of experimental steel shovel teeth and the experimental conclusion summed up as follows:

(1) Determine the optimization composition of experimental steel (wt \%): C: 0.5、Si: 1.2、Mn: 1.2、 Ni: 0.5、Mo: 0.3、Cr: 2.5. Determine the optimization heat treatment plan: $920^{\circ} \mathrm{C} \times 2 \mathrm{~h}$ austenitizing and $290^{\circ} \mathrm{C} \times 2 \mathrm{~h}$ isothermal quenching. Under the best composition and the optimal technology, material hardness is 48-53 HRC, compared to the original in relieving raised 8-10 HRC and $\alpha_{\mathrm{k}}$ is $39-44 \mathrm{j} / \mathrm{cm}^{2}$.

(2) Impact toughness is slightly lower after rising first with the extension of isothermal time when the chromium content was $2.5 \%$ and toughness get peaked when time is $2 \mathrm{~h}$. Isothermal time had a little effects on hardness.

(3) When chromium content is more than $2.5 \%$, continue to increase its content, it has little contribution to the hardness growth, but has a sharp drop in impact toughness.

\section{Acknowledgements}

In this paper, the research was sponsored by Jiamusi university President entrepreneurial innovation fund (project number xzyf2013-05) and the national natural science foundation of China (project No. 51371090) and Jiamusi university graduate student innovation of science and technology (project LZR2014-007).

\section{References}

[1] Zailiang Chen, Yalan Li. The development of the mining excavator bucket teeth [J]. Journal of mining machinery, 1992, (9) : 37

[2] Stevenson A N, Hutchings I M. Wear of hard facing white cast irons by solid particle erosion [C]. 8th International Conference on Erosion by Liquid and Solid Impact, 1995, (1): 150-158

[3] Hongyu Chen, Guanghai Zheng, Jia-wen Xu. A failure analysis of excavator bucket tooth, [J]. Metal heat treatment, 2003, (8) : 66-67

[4] Hongsheng Fang. Bainite and bainite steel [J]. Metal heat treatment, 1999 (11) : 38-42

[5] Jiwei Guo. Carbon and silicon content and heat treatment parameters effect on the properties of bainite steel [J]. Mechanical engineers, 2003. 3

[6] Dawson J V. Vanadium in Cast Iron [J]. The British Foundryman, 1982(3): 75-78

[7] ShouFan Rong. The influence of quenching process and carbon content on mechanical properties of bainitesteel [J]. Journal of Harbin University of science and technology, 2000.3. 3

[8] Mechanical manufacturing process institute of Shanghai. Metallographic analysis technology [M]. Shanghai: Shanghai scientific literature publishing house, 1987

[9] Jingpei Xie, Wei Li. Wear-resisting cast steel and smelting [M]. Beijing: mechanical industry publishing house, 2003

[10] Bingxing Chen. The research of low alloy wear resistant cast steel heat treatment process [D]. Shanghai: Donghua University, 2009 